Article

\title{
Dietary Administration of Olive Mill Wastewater Extract Reduces Campylobacter spp. Prevalence in Broiler Chickens
}

\author{
Raffaella Branciari ${ }^{1}$, David Ranucci ${ }^{1}$, Roberta Ortenzi ${ }^{2}$, Rossana Roila ${ }^{2}$, \\ Massimo Trabalza-Marinucci ${ }^{1, *}$, Maurizio Servili ${ }^{3}$, Paola Papa ${ }^{2}$, Roberta Galarini ${ }^{2}$ and \\ Andrea Valiani ${ }^{2}$ \\ 1 Department of Veterinary Medicine, University of Perugia, Via S. Costanzo 4, Perugia 06126, Italy; \\ raffaella.branciari@unipg.it (R.B); david.ranucci@unipg.it (D.R.) \\ 2 Istituto Zooprofilattico Sperimentale dell'Umbria e delle Marche, Via G. Salvemini 1, Perugia 06126, Italy; \\ r.ortenzi@izsum.it (R.O.); r.roila@izsum.it (R.R.); p.papa@izsum.it (P.P.); r.galarini@izsum.it (R.G.); \\ a.valiani@izsum.it (A.V.) \\ 3 Department of Agricultural, Food and Environmental Sciences, University of Perugia, Borgo XX Giugno 74, \\ Perugia 06121, Italy; maurizio.servili@unipg.it \\ * Correspondence: massimo.trabalza@unipg.it; Tel.: +39-075-585-7707
}

Academic Editors: Francesco Asdrubali and Pietro Buzzini

Received: 17 June 2016; Accepted: 19 August 2016; Published: 24 August 2016

\begin{abstract}
Food wastes are sources of compounds that can be used as natural additives in the food and feed industry. The olive oil industry produces two main wastes: aqueous waste (olive mill wastewater) and solid waste (pomace or olive cake). These by-products are rich in phenols, which are antioxidant and antimicrobial compounds able to inhibit or delay the growth of several bacteria in vitro. The dietary effect of both olive mill wastewater polyphenolic extract (OMWPE) and dehydrated olive cake (DOC) on the prevalence of Campylobacter spp. in broiler chickens was investigated. A commercial basal diet was supplemented with either OMWPE- or DOC-enriched maize at two dosages (low: 16\%; high: 33\%). The prevalence of Campylobacter spp. shedding was evaluated at 21,35, and 49 days of age. The prevalence of Campylobacter spp. differed among groups only at 49 days of age. Both OMWPE groups showed a lower $(p<0.05)$ prevalence compared to the control group. The odds ratio evaluation showed that the higher dose of OMWPE reduced the possibility of shedding 11-fold compared to the control group $(p<0.001)$. These results highlight the potential use of olive by-products against Campylobacter spp. in poultry.
\end{abstract}

Keywords: broiler; olive mill by-products; polyphenols; microbial shedding

\section{Introduction}

Food waste is a major concern, as serious environmental issues are posed and limited options are available. This problem is intensified by slow progress in the development of effective waste management strategies and by the lack of legislation to regulate specific food waste discharge. Nonetheless, food waste is a valuable source of compounds that can be used in industrial applications. Olive oil extraction generates substantial amounts of by-products: a solid residue (olive pomace or olive cake) and an aqueous phase (olive mill wastewater), both of which are potential pollutants. Both are currently treated as industrial wastes or used as combustible material, heavy-metal absorbers and biofuel feedstock [1,2]. However, these by-products are relatively rich in polyphenols. Polyphenols are bioactive molecules commonly used as antioxidants and antimicrobials in the food industry [3-5]. One important alternative is the utilization of by-products from olive tree culture and the olive oil industry as sources of nutrients for animals [6]. Furthermore, new technologies based on membrane 
treatments of aqueous by-products have been used to recover the crude phenolic concentrate rich in secoiridoids, especially 3,4-DHPEA-EDA and verbascoside [7], which can be used in industrial and feed applications. The valorisation of polyphenols, extracted from olive mill wastewater or available in stone-dried pomaces, as supplements in animal diets appears interesting for the possible bioactive effects on meat quality and animal welfare [8-10].

However, studies on in vivo antimicrobial effects and animal health and foodborne pathogen colonization and shedding are scarce. Campylobacter spp. is the main bacteria responsible for foodborne outbreaks in humans through chicken meat consumption [11]. The aim of this study was to evaluate the effects of dietary supplementation with two olive mill by-products, olive mill wastewater polyphenol extract (OMWPE) and dehydrated olive cake (DOC), on the shedding of Campylobacter spp. in broilers.

\section{Experimental Section}

\subsection{Experimental Design and Animal Management}

The two supplements used in the present experiment were obtained from the processing of Italian cultivar Moraiolo of Olea europea through the dehydration of olive cake obtained by oil mechanical extraction from stone olives (DOC): for the aqueous waste, the supplement was obtained through the use of a filtration system with progressive permeability membranes (OMWPE) [12]. Both olive mill by-products were used in the production of a grower diet for broilers, fed from 22 to 49 days of age. To facilitate the feed processing and allow a correct distribution of the supplement within the feed matrix, a maize meal enriched with either OMWPE or DOC (provided by a local feed plant) was used. Briefly, maize flour (600 $\mu \mathrm{m}$ particle size) was thoroughly mixed with either OMWPE or DOC in a 30:70 or 50:50 proportion, respectively, and then dried $(12 \mathrm{~h})$ in a forced air oven at $60{ }^{\circ} \mathrm{C}$. The enriched meal was used in two concentrations: 16\% (L-OMWPE and L-DOC) and 33\% (H-OMWPE and $\mathrm{H}-\mathrm{DOC})$. The highest dosage was chosen on the basis of previous studies on the use of dietary polyphenols in poultry and taking into consideration the estimated polyphenol content of the diet before pelleting [13,14]. An excessive polyphenol intake may have pro-oxidant activity [9].

The control group was fed a non-supplemented basal diet. All diets were isoenergetic, isonitrogenous and provided similar amounts of structural carbohydrates (Table 1). Rations were formulated to meet National Research Council standards [15]. The total concentrations measured for polyphenols in feed were obtained adding the individual concentrations of four compounds: tyrosol, hydroxytyrosol, pinoresinol and verbascoside. The identification and quantification of each compound was carried out by liquid chromatography tandem mass spectrometry (LC-MS/MS) in negative electrospray ionization (ESI) mode [16]. The LC-MS/MS system consisted of a Finnigan Surveyor LC pump combined with a triple stage quadrupole (TSQ) Quantum Ultra (Thermo Scientific, San Jose, CA, USA). The chromatographic separation was achieved using a Gemini analytical column $(100 \mathrm{~mm} \times 2.0 \mathrm{~mm}, 3 \mu \mathrm{m}$, Phenomenex, Torrance, CA, USA) with methanol and water as mobile phases. Samples were prepared as follows: five grams of feed were extracted twice with a mixture methanol/water $80 / 20(v / v)$ containing $20 \mathrm{mg} / \mathrm{L}$ of BHT $(2 \times 25 \mathrm{~mL})$. Two aliquots of the extract, $1 \mathrm{~mL}$ and $100 \mu \mathrm{L}$, were both diluted to $5 \mathrm{~mL}$ with a mixture $\mathrm{Na}_{2}$ EDTA $0.1 \mathrm{M} /$ methanol 90/10 $(v / v)$. After filtration, the two aliquots were injected separately in LC-MS/MS. The instrument linearity range was studied from 1 to $1000 \mathrm{ng} / \mathrm{mL}$. The validation study was performed at four levels: $0.1,0.5,5$ and $50 \mathrm{mg} / \mathrm{kg}$ (six replicates per level in two occasions: 48 experiments).

A total of 495 22-day-old female chicks (Ross 308) were randomly assigned to five experimental grower diets (control CTR, L-DOC, H-DOC, L-OMWPE, and H-OMWPE) with three replicates of 33 birds each. The same starter diet (Table 1) was used for all experimental groups up to 21 days of age. The birds were supplied with feed and water ad libitum during the whole length of the trial and raised in an experimental farm with environmental conditions similar to those commonly found in industrial poultry houses. 
Table 1. Chemical composition of the experimental diets.

\begin{tabular}{ccccccc}
\hline & \multirow{2}{*}{ Starter } & \multicolumn{5}{c}{ Grower/Finisher } \\
\cline { 3 - 7 } & & Control & L-DOC & H-DOC & L-OMWPE & H-OMWPE \\
\hline Moisture \% & 10.10 & 9.65 & 10.19 & 10.17 & 9.64 & 9.72 \\
Crude Protein \% & 22.24 & 19.56 & 19.46 & 19.19 & 20.09 & 19.54 \\
NDF \% & 17.93 & 22.14 & 22.16 & 23.52 & 23.58 & 22.50 \\
Starch \% & 38.59 & 41.40 & 41.48 & 40.39 & 40.67 & 41.30 \\
\hline
\end{tabular}

L-DOC = concentrate containing 16\% DOC-enriched maize meal; $\mathrm{H}-\mathrm{DOC}=$ concentrate containing $33 \%$ DOC-enriched maize meal; L-OMWPE = concentrate containing 16\% OMWPE-enriched maize meal; HOMWPE = concentrate containing 33\% OMWPE-enriched maize meal.

During the experiment, faeces were collected by cloacal swab to evaluate the efficacy of the diet in controlling the spread of Campylobacter spp. The faecal samples were collected randomly from 15 chickens for each replicate at 21 (i.e., before starting the administration of the experimental diets), 35 and 49 days of age (age of slaughtering) and sent under refrigerated conditions $\left(4 \pm 1{ }^{\circ} \mathrm{C}\right)$ to the laboratory for microbiological analyses, which were performed within $2 \mathrm{~h}$ from the sampling. All animals were weighed at the beginning and at the end of the trial. Carcasses were weighed after chilling and the dressing percentage was calculated as the ratio between final live weight and carcass weight.

\subsection{Campylobacter spp. Isolation and Identification}

For Campylobacter spp. isolation, selective enrichment was performed by incubating each swab sample microareobically in $10 \mathrm{~mL}$ of Preston broth (Oxoid, Basingstoke, UK) at $41.5^{\circ} \mathrm{C} \pm 1{ }^{\circ} \mathrm{C}$ for $44 \mathrm{~h} \pm 4 \mathrm{~h}$. One loopful of broth culture was then streaked onto selective medium MCCD Agar (Biolife Italian s.r.l., Milan, Italy) and Karmali Agar (Oxoid), incubated at $41.5^{\circ} \mathrm{C} \pm 1{ }^{\circ} \mathrm{C}$ for $44 \mathrm{~h} \pm 4 \mathrm{~h}$ in microaerobic conditions. At the end of the incubation period, Campylobacter typical colonies were cultured on blood agar medium ( $5 \%$ sheep red blood cells) (Biolife) and incubated at $41.5^{\circ} \mathrm{C} \pm 1{ }^{\circ} \mathrm{C}$ for $24-48 \mathrm{~h}$ in microaerobic conditions. Starting from the pure isolated cultures, colonies were tested through a morphological and biochemical identification (Gram stain, catalase test, oxidase test). Samples were considered positive when colonies presented morphological characteristics typical of the genus Campylobacter and were positive to oxidase and catalase. Subsequently, DNA was extracted from these colonies, isolated and amplified using multiplex PCR by simultaneous amplification of the genes of different species of Campylobacter in a single PCR reaction (multiplex) by the use of specific primers for the gene coding for the $23 \mathrm{~S}$ ribosomal RNA of Campylobacter species [17].

\subsection{Statistical Analyses}

The data obtained were used to calculate the prevalence of shedding in all groups. The obtained prevalence was analysed by ANOVA (Statview SAS Institute Inc., Cary, NC, USA) with diet and sampling time as fixed factors. In addition, using data obtained from samples taken at slaughtering, a chi-square test (WINPEPI: PEPI-for-Windows freeware) was also performed to directly compare each experimental group to the control group and the odds ratio (and its $95 \%$ confidence intervals) was calculated to determine the probability level of detecting shedding animals. Performance data were analysed by ANOVA with diet as the fixed factor. Difference between least square means were evaluated using the Tukey test. The differences were considered significant at $p<0.05$.

\section{Results and Discussion}

The five experimental diets contained the following amounts of polyphenols: control, $0.004(\mathrm{~g} / \mathrm{kg})$; L-DOC, 0.014 (g/kg); H-DOC, 0.024 (g/kg); L-OMWPE, 0.263 (g/kg); H-OMWPE, 0.556 (g/kg). The prevalence of animal shedding Campylobacter spp. in the five groups considered is reported in Table 2. Even though the trials were performed under controlled conditions, inside each group 
a relevant diffusion of Campylobacter spp. was detected as the shedding rate increased from 21 to 35 days of age in almost all the groups (Figure 1). An increasing in the shedding percentage was also noticed from 35 to 49 days, but only in the control and the L-DOC group, while a stable or a reduction trend was recorded in the other groups, with significant differences only observed for L-OMWPE and H-OMWPE vs. control $(p<0.01)$. The high prevalence of Campylobacter spp. observed in the trial is considered typical in poultry flocks, as the rate of infection is relevant [18]. The high excretion rate generally provides, in a few days, a high degree of infection among the chickens of the same flock [19]. The use of various polyphenol doses seemed to affect the Campylobacter spp. shedding rate only after a prolonged period of administration ( 28 days).

Table 2. Average prevalence ( $\% \pm$ standard deviation) of animal shedding Campylobacter spp. of control and the four trial groups at the three sampling periods considered.

\begin{tabular}{ccccccc}
\hline & Control & L-DOC & H-DOC & L-OMWPE & H-OMWPE & $p$ Value \\
\hline 21 days & $40.00 \pm 6.67$ & $40.00 \pm 13.33$ & $20.00 \pm 11.55$ & $26.27 \pm 13.33$ & $24.44 \pm 13.88$ & 0.212 \\
35 days & $57.78 \pm 10.18 \mathrm{ab}$ & $57.78 \pm 3.85 \mathrm{ab}$ & $60.00 \pm 6.67 \mathrm{~b}$ & $80.00 \pm 13.33 \mathrm{ab}$ & $46.67 \pm 6.67 \mathrm{a}$ & 0.012 \\
49 days & $75.56 \pm 3.85 \mathrm{~b}$ & $71.11 \pm 3.88 \mathrm{~b}$ & $68.89 \pm 3.85 \mathrm{~b}$ & $31.11 \pm 16.78 \mathrm{a}$ & $20.00 \pm 6.67 \mathrm{a}$ & $<0.001$ \\
\hline
\end{tabular}

L-DOC = concentrate containing 16\% DOC-enriched maize meal; H-DOC = concentrate containing 33\% DOC-enriched maize meal; L-OMWPE = concentrate containing 16\% OMWPE-enriched maize meal; HOMWPE $=$ concentrate containing 33\% OMWPE-enriched maize meal. ANOVA model. Different letters in the same row denote significant difference $(p<0.05)$.

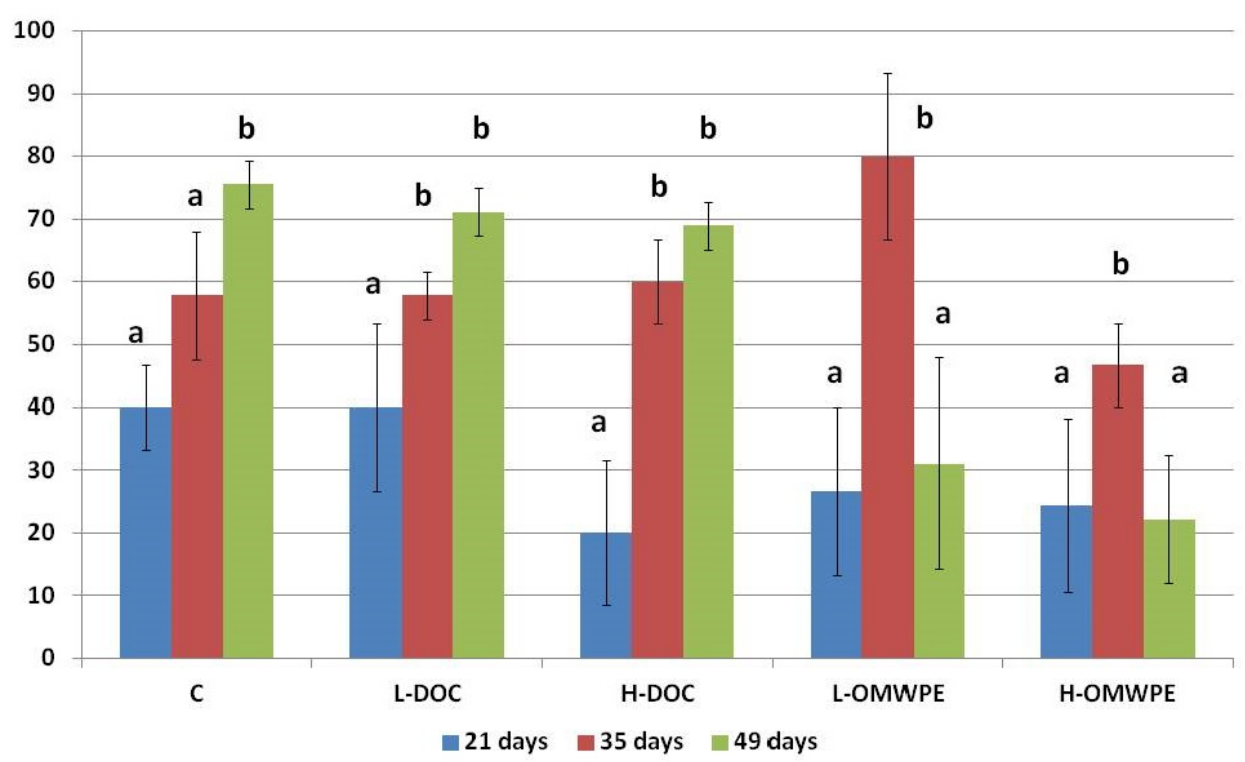

Figure 1. Average prevalence ( $\% \pm$ standard deviation) of animal shedding of Campylobacter spp. at each of the three sampling periods. L-DOC = concentrate containing 16\% DOC-enriched maize meal; $\mathrm{H}-\mathrm{DOC}=$ concentrate containing 33\% DOC-enriched maize meal; L-OMWPE = concentrate containing 16\% OMWPE-enriched maize meal; H-OMWPE = concentrate containing 33\% OMWPE-enriched maize meal. ANOVA Model. Different letters in the same row denote significant difference $(p<0.05)$.

Previous studies have focused on the effects of olive by-product polyphenols on foodborne pathogens in in vitro trials $[20,21]$, typically involving Gram-negative bacteria. No data are available on Campylobacter spp. both in in vitro and in vivo trials. Nonetheless, Campylobacter spp. seems to be sensitive to polyphenol compounds derived from other products [22]. The use of polyphenols from grape seed shows a strong capacity to inhibit Campylobacter spp. growth from 5 to 7 Log colony forming unit/g, and a minimal inhibitory concentration (MIC) of $20 \mathrm{mg} / \mathrm{L}$ and a minimal bactericidal concentration (MBC) of $60 \mathrm{mg} / \mathrm{L}$ against Campylobacter jejuni [23]. Furthermore, the MIC and MBC of blackberry pomace extract against Campylobacter jejuni were $0.6 \mathrm{mg} / \mathrm{mL}$ and $0.8 \mathrm{mg} / \mathrm{mL}$ Gallic 
Acid Equivalent (GAE) respectively, whereas the MIC and MBC of blueberry pomace extract were $0.4 \mathrm{mg} / \mathrm{mL}$ and $0.5 \mathrm{mg} / \mathrm{mL}$ GAE [24]. The effect of a number of natural feed additives against Campylobacter spp. colonization in poultry has been previously studied by Kurecki et al. [25]. However, the used compounds were not comparable to the bioactive molecules considered in this study and the results were not consistent.

The higher amounts of polyphenols contained in the OMWPE diets are likely responsible for the observed effects on Campylobacter spp. shedding. The concentrations of polyphenols in poultry fed with maize meal enriched with dehydrated olive cake were too low to exert a significant action against the microorganisms.

The statistical analysis highlights the presence of differences between the control and OMWPE groups at 49 days, with a higher odds ratio for H-OMWPE (Table 3). A significant reduction of Campylobacter spp. faecal shedding was found for OMWPE diets only. These results suggest that, at the experimental conditions adopted, this polyphenol extract can be usefully included in broiler diets to control Campylobacter spp. shedding at the end of the production lifespan.

Table 3. Chi square test, odds ratio and confidence intervals of control group versus the other experimental group at 49 days of age.

\begin{tabular}{cccccc}
\hline & $\mathbf{X}^{\mathbf{2}}$ & $\boldsymbol{p}$ Value & Odds Ratio & CI 95\% Min & CI 95\% Max \\
\hline CTR v L-DOC & 0.22 & 0.63 & 1.26 & 0.49 & 3.20 \\
CTR v H-DOC & 0.50 & 0.48 & 1.40 & 0.55 & 3.52 \\
CTR v L-OMWPE & 19.64 & $<0.001$ & 7.61 & 2.98 & 19.42 \\
CTR v H-OMWPE & 25.61 & $<0.001$ & 10.82 & 4.07 & 28.76 \\
\hline
\end{tabular}

L-DOC = concentrate containing 16\% DOC-enriched maize meal; $\mathrm{H}-\mathrm{DOC}=$ concentrate containing $33 \%$ DOC-enriched maize meal; L-OMWPE = concentrate containing 16\% OMWPE-enriched maize meal; H-OMWPE = concentrate containing 33\% OMWPE-enriched maize meal.

As for the performance data reported in Table 4, the birds fed with H-DOC and L-OMWPE diets reached final live weights higher than those of the control animals $(p<0.05)$. No differences were recorded among the other experimental groups. Higher carcass weight was observed for the L-OMWPE group compared to the CTR group. In contrast, no dietary effects on the dressing percentage were recorded. There is a dearth of data in the literature concerning the effect of olive mill by-products on broiler performance. To the best of our knowledge, DOC and OMWPE have not previously been used in broiler nutrition. Hughes et al. [26] used olive cake in broiler diets $(7.2 \mathrm{~g} / \mathrm{kg})$ and observed lower weight gains in comparison to the control animals. Other results obtained after feeding broilers by-products rich in polyphenols are not consistent. Any comparison should be performed with caution because the feed characteristics and management practices adopted in these trials are extremely variable $[14,27,28]$.

Table 4. Effect of dietary treatment on live weight, carcass weight, and dressing percentage.

\begin{tabular}{cccccccc}
\hline & CTR & L-DOC & H-DOC & L-OMWPE & H-OMWPE & SE & $p$ Value \\
\hline Live weight & $1.88 \mathrm{~b}$ & $2.02 \mathrm{ab}$ & $2.17 \mathrm{a}$ & $2.18 \mathrm{a}$ & $1.94 \mathrm{ab}$ & 0.059 & 0.017 \\
Carcass weight & $1.41 \mathrm{~b}$ & $1.51 \mathrm{ab}$ & $1.58 \mathrm{ab}$ & $1.64 \mathrm{a}$ & $1.42 \mathrm{~b}$ & 0.053 & 0.045 \\
Dressing percentage & 74.71 & 74.41 & 72.69 & 75.28 & 73.13 & 0.726 & 0.134 \\
\hline
\end{tabular}

L-DOC = concentrate containing 16\% DOC-enriched maize meal; H-DOC = concentrate containing 33\%

DOC-enriched maize meal; L-OMWPE = concentrate containing 16\% OMWPE-enriched maize meal; H-OMWPE = concentrate containing 33\% OMWPE-enriched maize meal. SE = standard error of the mean. Different letters in the same row denote significant difference $(p<0.05)$.

\section{Conclusions}

The results obtained highlight the possible use of olive waste by-products in chicken diets to reduce the risk of Campylobacter spp. diffusion in the flock and consequently in meat. Further studies 
are needed to evaluate whether dietary OMWPE administered throughout the chicken lifespan could also be used to prevent the colonization of Campylobacter spp. without any detrimental effect on performance. Finally, an improvement of feed technology to obtain DOCs with a higher polyphenol content should be explored with further research.

Acknowledgments: This work is part of a research project funded by the Italian Ministry of Health (CUP D98C13000130001—“Valutazione dell'effetto di una dieta integrata con polifenoli derivanti da reflui dell'industria elaiotecnica sulle caratteristiche igienico-sanitarie, chimico-fisiche, reologiche e organolettiche della carne fresca e delle preparazioni di carne: filiera del pollo da carne").

Author Contributions: Andrea Valiani planned the study and coordinated the Istituto Zooprofilattico Sperimentale group composed by: Rossana Roila who collected the samples, Roberta Ortenzi and Paola Papa who performed the microbiological analysis, Roberta Galarini who performed polyphenol analysis in feeds, Massimo Trabalza-Marinucci who developed the chicken diet and performed the proximate composition of feed, Raffaella Branciari who co-planned the study and wrote the manuscript, David Ranucci who collected data and performed a statistical evaluation. Maurizio Servili of the Department of Agricultural, Food and Environmental Sciences implemented the technology for the use of olive by-products as feed additives.

Conflicts of Interest: The authors declare no conflict of interest.

\section{References}

1. Dermeche, S.; Nadour, M.; Larroche, C.; Moulti-Mati, F.; Michaud, P. Olive mill wastes: Biochemical characterizations and valorization strategies. Process Biochem. 2013, 48, 1532-1552. [CrossRef]

2. Messineo, A.; Volpe, R.; Asdrubali, F. Evaluation of net energy obtainable from combustion of stabilized olive mill by-products. Energies 2012, 5, 1384-1397. [CrossRef]

3. Goula, A.M.; Lazarides, H.N. Integrated processes can turn industrial food waste into valuable food by-products and/or ingredients: The cases of olive mill and pomegranate wastes. J. Food Eng. 2015, 167, 45-50. [CrossRef]

4. Carraro, L.; Fasolato, L.; Montemurro, F.; Martino, M.E.; Balzan, S.; Servili, M.; Novelli, E.; Cardazzo, B. Polyphenols from olive mill waste affect biofilm formation and motility in Escherichia coli K-12. Microb. Biotechnol. 2014, 7, 265-275. [CrossRef] [PubMed]

5. Zbakh, H.; El Abbassi, A. Potential use of olive mill wastewater in the preparation of functional beverages: A review. J. Funct. Foods 2012, 4, 53-65. [CrossRef]

6. Molina Alcaide, E.; Nefzaoui, A. Recycling of olive oil by-products: Possibilities of utilization in animal nutrition. Int. Biodeterior. Biodegrad. 1996, 38, 227-235. [CrossRef]

7. Servili, M.; Esposto, S.; Taticchi, A.; Urbani, S.; Di Maio, I.; Veneziani, G.; Selvaggini, R. New approaches to virgin olive oil quality, technology, and by-products valorization. Eur. J. Lipid Sci. Technol. 2015, 117, 1882-1892. [CrossRef]

8. Dal Bosco, A.; Castellini, C.; Cardinali, R.; Mourvaki, E.; Moscati, L.; Battistacci, L.; Servili, M.; Taticchi, A. Olive cake dietary supplementation in rabbit: Immune and oxidative status. Ital. J. Anim. Sci. 2007, 6 (Suppl. S1), 761-763. [CrossRef]

9. Dal Bosco, A.; Mourvaki, E.; Cardinali, R.; Servili, M.; Ruggeri, S.; Mattioli, S.; Taticchi, A.; Esposto, S.; Castellini, C. Effect of dietary supplementation with olive pomaces on the performance and meat quality of growing rabbits. Meat Sci. 2012, 92, 783-788. [CrossRef] [PubMed]

10. Branciari, R.; Ranucci, D.; Miraglia, D.; Urbani, S.; Esposto, S.; Servili, M. Effect of dietary treatment with olive oil by-product (olive cake) on physico-chemical, sensory and microbial characteristics of beef during storage. Ital. J. Food Saf. 2015, 4, 225-229. [CrossRef]

11. European Food Safety Authority. The European Union summary report on trends and sources of zoonoses, zoonotic agents and food-borne outbreaks in 2013. EFSA J. 2015, 13, 3991-4156.

12. Servili, M.; Esposto, S.; Veneziani, G.; Urbani, S.; Taticchi, A.; Di Maio, I.; Selvaggini, R.; Sordini, B.; Montedoro, G.F. Improvement of bioactive content in virgin olive oil with an olive-vegetation water concentrate produced by membrane treatment. Food Chem. 2011, 124, 1308-1315. [CrossRef]

13. Tang, S.Z.; Kerry, J.P.; Sheehan, D.; Buckley, D.J.; Morrissey, P.A. Dietary tea catechins and iron-induced lipid oxidation in chicken meat, liver and heart. Meat Sci. 2000, 56, 285-290. [CrossRef] 
14. Brenes, A.; Viveros, A.; Goñí, I.; Centeno, C.; Sayago-Ayerdy, S.G.; Arija, I.; Saura-Calixto, F. Effect of grape pomace concentrate and vitamin $\mathrm{E}$ on digestibility of polyphenols and antioxidant activity in chickens. Poult. Sci. 2008, 87, 307-316. [CrossRef] [PubMed]

15. National Research Council. Nutrient Requirements of Poultry, 9th Revised Edition; National Academic Press: Washington, DC, USA, 1994; pp. 26-32.

16. Galarini, R.; Giusepponi, D.; Moretti, S.; Saluti, G.; Ortenzi, R.; Valiani, A. Residues in poultry fed with high content of polyphenols. In Proceedings of the EuroResidue VIII Conference, Egmond aan Zee, The Netherlands, 23-25 May 2016.

17. Wang, G.; Clark, C.G.; Taylor, T.M.; Pucknell, C.; Barton, C.; Price, L.; Woodward, D.L.; Rodgers, F.G. Colony Multiplex PCR Assay for identification and differentiation of Campylobacter jejuni, C. coli, C. lari, C. upsaliensis, and C. fetus subsp. fetus. J. Clin. Microbiol. 2002, 40, 4744-4747. [CrossRef] [PubMed]

18. Miraglia, D.; Ranucci, D.; Branciari, R.; Cioffi, A.; Mammoli, R.; Cenci Goga, B.T.; Avellini, P. Prevalence of Campylobacter jejuni and Campylobacter coli in chicken hybrids with different growth rates, reared according to conventional and "Free-Range" production methods. Vet. Res. Commun. 2007, 31 (Suppl. S1), 381-384. [CrossRef] [PubMed]

19. Sahin, O.; Kassem, I.I.; Shen, Z.; Rajashekara, G.; Zhang, Q. Campylobacter in poultry: Ecology and potential interventions. Avian Dis. 2015, 59, 185-200. [CrossRef] [PubMed]

20. Medina, E.; Brenes, M.; Garcia, A.; Romero, C.; de Castro, A. Bactericidal activity of Glutaraldehyde-like compounds from olive products. J. Food Prot. 2009, 12, 2611-2614.

21. Larif, M.; Ouhssine, M.; Soulaymani, A.; Elmidaoui, A. Potential effluent oil mills and antibacterial activity polyphenols against some pathogenic strains. Res. Chem. Intermed. 2015, 41, 1213-1225. [CrossRef]

22. Gañan, M.; Martínez-Rodríguez, A.J.; Carrascosa, A.V. Antimicrobial activity of phenolic compounds of wine against Campylobacter jejuni. Food Control 2009, 20, 739-742. [CrossRef]

23. Silván, J.M.; Mingo, E.; Hidalgo, M.; de Pascual-Teresa, S.; Carrascosa, A.V.; Martinez-Rodriguez, A.J. Antibacterial activity of a grape seed extract and its fractions against Campylobacter spp. Food Control 2013, 29, 25-31. [CrossRef]

24. Salaheen, S.; Nguyen, C.; Hewes, D.; Biswas, D. Cheap extraction of antibacterial compounds of berry pomace and their mode of action against the pathogen Campylobacter jejuni. Food Control 2014, 46, 174-181. [CrossRef]

25. Kurekci, C.; Al Jassim, R.; Hassan, E.; Bishop-Hurley, S.L.; Padmanabha, J.; McSweeney, C.S. Effects of feeding plant-derived agents on the colonization of Campylobacter jejuni in broiler chickens. Poult. Sci. 2014, 93, 1-10. [CrossRef] [PubMed]

26. Hughes, R.J.; Brooker, J.D.; Smyl, C. Growth rate of broiler chickens given condensed tannins extracted from grape seed. Aust. Poult. Sci. Symp. 2005, 17, 65-68.

27. Viveros, A.; Chamorro, S.; Pizarro, M.; Arija, I.; Centeno, C.; Brenes, A. Effects of dietary polyphenol-rich grape products on intestinal microflora and gut morphology in broiler chicks. Poult. Sci. 2011, 90, 566-578. [CrossRef] [PubMed]

28. Goñi, I.; Brenes, A.; Centeno, C.; Viveros, A.; Saura-Calixto, F.; Rebole, A.; Arija, I.; Estevez, R. Effect of dietary grape pomace and vitamin $\mathrm{E}$ on growth performance, nutrient digest digestibility, and susceptibility to meat lipid oxidation in chickens. Poult. Sci. 2007, 86, 508-516. [CrossRef] [PubMed]

(C) 2016 by the authors; licensee MDPI, Basel, Switzerland. This article is an open access article distributed under the terms and conditions of the Creative Commons Attribution (CC-BY) license (http://creativecommons.org/licenses/by/4.0/). 